\title{
ATIVIDADES UTILIZADAS PARA EDUCAÇÃO SEXUAL NA ESCOLA
}

\author{
Thaís Emília de Campos, Raul Aragão Martins
}

Universidade Estadual Paulista - UNESP, Programa de Pós-graduação em Educação, Marília, SP. Agência de fomento: CNPQ. E-mail: thais.emilia@hotmail.com; raul@ibilce.unesp.br

\section{RESUMO}

Os adolescentes fazem parte de um grupo em situação de vulnerabilidade, pois são mais suscetíveis ao comportamento de risco. Entre esses comportamentos, temos os que envolvem sexualidade e uso de drogas como fatores de vulnerabilidade. Sexualidade é algo amplo, é a necessidade de receber e expressar afeto que proporciona sensações prazerosas. O objetivo deste estudo foi planejar e realizar atividades permanentes de educação sexual na escola com adolescentes. Esta pesquisa trata de um estudo de caso amplo, partindo de uma intervenção de educação sexual com alunos de uma escola de ensino fundamental e médio. Constatamos que Educação sexual é algo muito complexo, uma atuação cotidiana na escola é algo mais eficaz, mas a torna ainda mais complexa. Isso ocorre por, envolver, além dos aspectos biológicos e reprodutores, questões afetivas, antropológicas, sociais, culturais, políticas, legais e morais.

Palavras-chave: Adolescência, Educação Sexual, Autonomia Sexual

\section{ACTIVITIES USED FOR SEX EDUCATION IN SCHOOLS}

\begin{abstract}
Teenagers are part of a group vulnerable because they are more susceptible to risky behavior. Among these behaviors, we have those involving sexuality and drug use and vulnerability factors. Sexuality is something broad, is the need to receive and express affection that provides pleasurable sensations. The aim of this study was to identify and carry out permanent activities of sex education at school with teenagers that allow the construction of sexual autonomy. This research deals with a broad case study, based on a sex education intervention with students at an elementary and high school. Found that sexual education is very complex, an everyday activity at school is more effective, but makes it even more complex. This occurs, involving, in addition to biological and reproductive, emotional issues, anthropological, social, cultural, political, legal and moral.
\end{abstract}

Keywords: Adolescence, Sex Education, Sexual Autonomy 


\section{INTRODUÇÃO}

Sexualidade não se reduz a sexo ou reprodução, envolve o toque e a palavra que transmite prazer entre pessoas e que temos desde antes do nascimento. Conforme vamos crescendo, descobrimos o prazer provocado pelo contato sexual, através do estímulo que fazemos em nós mesmos ou com outras pessoas (REDE CE, 2015).

Para Zampieri (2004) e Jeolás (2006), os adolescentes fazem parte de um grupo em situação de vulnerabilidade, pois são mais suscetíveis ao comportamento de risco. Pois características próprias da adolescência levam a participação em atividades que podem comprometer sua saúde física e mental, devido à curiosidade e ao comportamento exploratório do jovem, a influência e importância de se inserir em grupos. Também a família são fatores que podem tornar o sujeito vulnerável a comportamentos de risco que tragam consequências para o seu desenvolvimento individual, familiar e social.

Em relação à família ser ou não vulnerável, estudo realizado por Pettengill e Angelo (2006), analisaram a compreensão do conceito de vulnerabilidade da família na área da saúde, evidenciando um processo dinâmico e contínuo. As pessoas podem racionalmente considerarem fatores de risco em seu modo de vida ou em sua vida, mas não experienciam a vulnerabilidade, porém se percebem ameaça ou perda da autonomia, exprimem o significado de vulnerabilidade para a família. A vulnerabilidade revela-se como condição do existir, manifestando-se em diferentes graus, de acordo com a situação, em todas as famílias. A família pode ser vista, ora como fator de proteção, ora como fator de vulnerabilidade, conforme a singularidade de cada situação. Há ocasiões que expõem mais a situações de risco ou não. Mas nem sempre a família tem a percepção se está num papel de proteção ou de vulnerabilidade. Muitas vezes, só percebem quando perderam a autonomia.

Essas questões nos fazem repensar a prevenção em saúde, estendendo a prevenção para o contexto escolar, com o objetivo de estimular o desenvolvimento da autonomia do jovem diante de sua vida sexual (FEIJÓ; OLIVEIRA, 2001).

A Educação Sexual nas escolas deveria envolver discussões sobre o direito ao prazer, ao exercício da sexualidade com responsabilidade e propiciar a construção da autonomia sexual dos adolescentes a fim de diminuir a vulnerabilidade às Doenças Sexualmente Transmissíveis e à Síndrome de Imunodeficiência Adquirida (DST/Aids), gestação não planejada e não desejada, e outros aspectos que a falta de autonomia podem levar a diferentes formas de sofrimento físico e emocional. Engloba, assim, relações de gênero, o respeito a si mesmo e ao outro e à diversidade 
de crenças, valores e expressões culturais existentes numa sociedade democrática e pluralista (CAMPOS, 2015).

Neste contexto, pesquisas apontam (AYRES, 2002; 2003) que pode-se trabalhar em busca da construção da autonomia através da reflexão de situações, utilizando o trabalho de alunos multiplicadores entre pares, pois a educação sexual faz-se com o acesso às informações e tendo um colega da mesma idade, que utiliza-se da mesma linguagem sempre acessível e à disponibilidade de preservativos rotineiramente, aumenta-se a eficácia do acesso a informação e a obtenção de preservativos. Os adolescentes devem ser capazes de construir normas entre iguais, optando por segui-las, pois, assim, participam de sua construção e verificam os benefícios que a norma pode ter para o seu grupo (MENIN, 2002).

O objetivo deste estudo foi planejar e realizar atividades permanentes de educação sexual na escola com adolescentes.

\section{METODOLOGIA}

Esta pesquisa trata de um estudo de caso amplo, partindo de uma intervenção com alunos de uma escola pública de ensino fundamental e médio, situada numa cidade do interior paulista com cerca de 400 mil habitantes. Sendo participantes da pesquisa 1350 alunos adolescentes, sendo 7 alunos multiplicadores, duas estagiárias da graduação em pedagogia, um docente da Unesp e a pesquisadora.

A escola foi escolhida por já possuir parceria com uma das unidades da Universidade Estadual Paulista "Júlio de Mesquita Filho" (UNESP) e a Secretaria Municipal de Saúde (SMS) de uma cidade do interior paulista, sendo este trabalho de Educação Sexual na escola decorrente de um projeto de extensão universitária da UNESP, intitulado "Formação de agentes multiplicadores para divulgação e uso de medidas preventivas às DST/Aids entre universitários e alunos de ensino médio", conhecido como “Equipe de Apoio do IBILCE - E aí?!", existente desde 2003.

Antes de iniciar a coleta de dados, o projeto foi submetido à apreciação do Comitê de Ética da Faculdade de Filosofia e Ciências da Universidade Paulista - UNESP - Campus de Marília e foi emitido parecer favorável em 21 de agosto de 2013, número 0803/2013.

Os participantes foram informados de que poderiam desistir de participar da pesquisa a qualquer momento, pois a participação é de livre consentimento. Além disso, foi informado aos alunos e à direção/coordenação das escolas que dados individuais não seriam fornecidos por se tratar de dados sigilosos. 
Participaram da pesquisa os alunos (maiores de 18 anos) que assinaram o Termo de Consentimento Livre Esclarecido - TCLE ou foi assinado pelos pais ou responsável (menores de 18 anos). Os professores participantes também assinaram esse documento. A direção da escola também autorizou a pesquisa na escola, tanto a intervenção quanto a aplicação do instrumento.

Foram utilizados os seguintes materiais: preservativos masculinos e femininos, prótese do órgão reprodutor masculino e feminino, vídeos, murais, cartolinas e outros materiais escolares.

Os alunos multiplicadores participaram de encontros semanais com duração de uma hora durante um ano letivo. Nesses encontros foram realizadas capacitações, reflexões e planejamento de atividades para serem aplicadas com os demais alunos da escola, envolvendo as seguintes atividades e temas: criação da Caixa de Dúvidas e divulgação na escola; criação e divulgação do facebook, Ask e conta de e-mail como mais um meio de informações aos adolescentes e tira dúvidas; anatomia e fisiologia dos órgãos reprodutores e confeç̧ão de cartazes; vídeos sobre homossexualidade para refletir sobre as questões de gênero, demanda criada devida ao projeto de "Cura Gay" de um político; menstruação e Tabelinha, vídeo para todos os alunos do fundamental II e tira dúvidas; métodos anticoncepcionais, ou seja, Minipílula injeção, implante dérmico, Dispositivo Intra Uterino (DIU), camisinha; dinâmica e confecção de sacolinhas surpresas com preservativos sobre o dia dos namorados; oficina de colocação do preservativo masculino; ciúmes, respeito e fidelidade; participação no Congresso de Iniciação Científica - CIC da UNESP.

Os demais alunos da escola participaram de atividades rotineiras e constantes elaboradas pelos alunos multiplicadores, professor e pesquisadora, sendo: disposição de caixa de dúvidas na escola, sessões de tira dúvidas com cada classe da escola, exibição e discussão de vídeos, confecção de murais, acesso a preservativos e aos alunos multiplicadores, oficina de colocação de preservativos masculino e feminino.

As atividades que os alunos multiplicadores realizaram com os alunos da escola ocorreram no período de março de 2013 a junho de 2014. Não foram elaborados instrumentos para avaliar a eficácia deste trabalho dos multiplicadores, os resultados foram analisados qualiquantitativamente nas dinâmicas utilizadas.

\section{RESULTADOS}

Na primeira reunião com os multiplicadores, em 2013, foi proposto aos alunos multiplicadores que escrevessem quatro palavras que vêm à mente quando escutam a palavra SEXO. Tivemos, assim, os seguintes resultados: 6 palavras relacionadas ’a afetividade, 4 relacionadas a consciência, 4 relativas ao ato sexual; 8 relacionadas a doenças, 3 palavras que indicaram o 
parceiro sexual e 3 palavras que se referem ao órgão sexual. Nenhum aluno citou palavras relacionadas a gravidez.

Em relação a caixa de dúvidas que foi disponibilizada no pátio da escola para todos alunos da escola depositarem anonimamente suas questões sobre sexo, com a tabulação dos dados pode-se constatar que das 77 dúvidas, 61,0\% delas referem-se a aspectos psicológicos, 39,00\% referem-se a aspectos biológicos (CAMPOS, 2015). Este dado não significa que os alunos tenham sanadas suas dúvidas dos aspectos biológicos sobre sexo, mas que há um maior interesse nas questões comportamentais.

O estudo de Ayres (2002) confirma que as campanhas iniciais com métodos terroristas, apresentam-se com poucos resultados; o histórico do perfil da epidemia do HIV nos mostra a necessidade de uma abordagem cada vez mais ampla e precoce, justificando a importância de se trabalhar o adolescente. E os dados da caixa de dúvida confirmam isto pois apresentam apenas $5 \%$ das questões relativas a preocupações com HIV e outras DST'S.

Nos diferentes contextos e meios, a utilização da informática na sociedade tornou-se um fato irreversível (AUGE, 2006), assim, por demanda criada pelos alunos foi criada uma página no facebook. Ela foi utilizada para veicular informações sobre prevenção, dicas sobre sexualidade e afetividade, porém eles não comentaram quase nenhuma postagem, a não ser fotos da escola e dos alunos, recados no grupo de multiplicares, também nunca enviaram questões "in box", alguns clicam em "curtir". Uma das multiplicadoras atribuiu isto ao fato da rede utilizada identificarem os usuários. Assim, criamos uma conta em outra rede social, ASK, que não aparece a identificação dos usuários e recebemos várias questões. Um dos alunos multiplicadores ficou responsável por administrar esta rede. Desta forma, os usuários desta rede podem deixar perguntas mantendo o anonimato.

As questões mais frequentes enviadas no ASK são relativas às formas de obtenção de prazer sexual, dúvidas sobre a anatomia e sensações do corpo do sexo oposto e sobre os métodos anticoncepcionais. As perguntas referentes a DST's aparecem com menos frequência do que as relacionadas à contracepção.

Nas sessões de exibição de vídeos para reflexão foram utilizados as seguintes produções: 1) vídeo “Menstruação" (RENNER, 2013), para alunos do Ensino Fundamental II e multiplicadores; 2) "Pai, mãe \& eu sou hetero" (PARAFERNALHA, 2013) para os alunos do Ensino Médio e multiplicadores; 3) "Não gosto de meninos" (MATARAZZO; FERRI, 2011) apenas com os alunos multiplicadores, isto devido a discussão trazida pelos multiplicadores em relação ao projeto de Cura Gay, onde alguns concordavam que homossexualidade é uma doença e outros discordavam. 
O uso desses vídeos mostraram-se grandes mobilizadores para iniciar discussões sobre os mais diversos temas: TPM, ciclo menstrual, primeira relação sexual, virgindade, gravidez e métodos anticoncepcionais; pílula do dia seguinte; constituição do gênero e padrões de sexualidades impostas; homossexualidade; namoro e privacidade nas redes sociais.

$\mathrm{Na}$ oficina do dia dos namorados confeccionamos sacolinhas surpresas, tratava de uma sacolinha com corações, preservativos aromatizados para estimular o uso no sexo oral protegido, balas de corações e pirulitos em forma de beijo. Durante a confecção das sacolinhas os alunos trouxeram os mais diversos assuntos para reflexão: virgindade, rompimento do hímen, uso do preservativo no sexo oral e prevenção de HPV, sexualidade dos pais e avós, relacionamento homo afetivo e uso do preservativo, fingir que não transa para os pais e ter que esconder os preservativos ou não carrega-los e a questão das vulnerabilidades.

Nas oficinas de colocação de preservativos foram mobilizados assuntos e questionamentos sobre formas de prazer através do sexo anal e sobre o tamanho do pênis.

$E$, nas sessões de tira dúvidas realizadas de tempo em tempo com cada classe da escola e equipe de multiplicadores e pesquisadora, geralmente as questões trazidas foram): pílula do dia seguinte, ponto G, como colocar o preservativo corretamente, possibilidades de engravidar.

\section{DISCUSSÃO}

No decorrer da intervenção na escola, alguns apontamentos e incômodos foram gerados por parte dos docentes, coordenadores e direção escolar, em relação ao trabalho com agentes multiplicadores entre pares, sendo: o projeto não ficar tão evidente para os visitantes da escola; temáticas propostas pelos alunos serem diferentes das esperadas pela equipe pedagógica; desacreditarem na capacidade dos multiplicadores para esclarecerem as dúvidas dos colegas; descentralização do poder e do controle da vida sexual dos alunos, principalmente quando a distribuição dos preservativos não é mais realizada pela coordenadora pedagógica e sim pelos alunos multiplicadores.

Esses incômodos são gerados por o intuito de nossas intervenções focarem a reflexão sobre condutas sexuais e o desenvolvimento da autonomia sexual dos alunos como forma de prevenção de DST/Aids e gravidez não-planejada, tendo como objetivo principal a vivência de uma sexualidade prazerosa e saudável.

Pesquisas atuais, como a de Ayres (2003) e Jeolás (2006) mostram que os adolescentes e jovens fazem parte de um grupo em situação de vulnerabilidade o que nos força a repensar a prevenção em saúde, estendendo o entendimento da prevenção para o espaço educacional, 
objetivando estimular o desenvolvimento da autonomia do jovem diante de sua vida sexual. Mas, esta busca da autonomia ainda carrega muitos tabus e preconceitos.

\section{CONCLUSÃO}

Educação sexual é algo muito complexo, uma atuação cotidiana na escola é algo mais eficaz, mas a torna ainda mais complexa. Isso ocorre por, envolver, além dos aspectos biológicos e reprodutores, questões afetivas, antropológicas, sociais, culturais, políticas, legais e morais. No geral, as escolas apresentam um discurso de educação sexual pautado numa moral religiosa e cristalizada em preceitos os quais contrariam a legislação que prevê um ensino laico e democrático. Também, geralmente esta pautada em aspectos biológicos e patológicos, resumindo-se a aulas de biologia e a palestras com profissionais da área de saúde de maneira isolada e descontextualizada as demandas reais dos alunos.

Quando trouxemos uma proposta e intervenção pertencente a rotina e cotidiano da escola, que permite o acesso a informação e a preservativos no cotidiano escolar, colocando-se em evidencia temas que são tidos como secretos ou tabus esbarra-se numa resistência atitudinal por parte da equipe escolar.

Essa resistência gera desequilíbrios que propiciaram reflexões necessárias e saudáveis ao ambiente escolar. Essas reflexões com os alunos e professores, partindo sempre de atividades e dinâmicas levaram a problematizações de situações que permitem a contribuição para o desenvolvimento da autonomia sexual dos adolescentes.

\section{REFERÊNCIAS}

AUGÉ, M. Sobre modernidade: do mundo tecnológico de hoje ao desafio essencial do amanhã. In: MORAES, D. (Org.). Sociedade midiatizada. Rio de Janeiro: Mauad, 2006. p. 99-117.

AYRES, J. R. C. M. Práticas educativas e prevenção de DST/AIDS: lições aprendidas e desafios atuais. Interface - Comunic., Saúde, Educ., São Paulo, v.6, n. 11, 2002. p. 11-24.

Adolescência e AIDS: avaliação de uma experiência de educação preventiva entre pares. Interface - Comunic., Saúde, Educ., São Paulo, v. 7, n. 12, 2003. p. 113-28.

CAMPOS, T. E. Educação sexual e autonomia: estudo de uma intervenção com alunos do ensino médio do interior do estado de São Paulo Dissertação (Mestrado em Educação) - Universidade Estadual Paulista, Faculdade de Filosofia e Ciências, 2015.

FEIJÓ, R.B.; OLIVEIRA, E.A. Comportamento de risco na adolescência. Jornal de Pediatria 77(2): S125-S134, 2001. http://dx.doi.org/10.2223/JPED. 300 
JEOLÁS, L. S.; Juventude, sexualidade e Aids: aspectos simbólicos da percepção do risco e da vulnerabilidade. In: FIGUEIRÓ, M. N. D.; RIBEIRO, P. R. M. (Org.) Adolescência em questão: estudos sobre sexualidade. Laboratório Editorial; Araraquara: FCL - UNESP, São Paulo: Cultura Acadêmica Editora, 2006.

MATARAZZO, A.; FERRI, G. Não gosto de meninos. Documentário, São Paulo: MASP, 2011.

MENIN, M. S. S. Valores na escola. Educação e Pesquisa, v. 28, n. 1, p. 91-100, 2002. http://dx.doi.org/10.1590/S1517-97022002000100006

PARAFERNALHA. Pai \& mãe, eu sou hetero. [s.l; s.n.] IN: https://www.youtube.com/watch?v=wDkN1d510kQ. Acesso em: 15 de março de 2013.

PETTENGILL, M.A.M.; ANGELO, M.. Identificação da vulnerabilidade da família na prática clínica. Rev. esc. enferm. USP, São Paulo, v. 40, n. 2, jun. 2006. Disponível em <http://www.scielo.br/scielo.php?script=sci_arttext\&pid=S008062342006000200018\&lng=pt\&nr m=iso>. acessos em 17 mar. 2015. http://dx.doi.org/10.1590/S0080-62342006000200018.

REDE CE. Rede Brasileira de Promoção de Informações e Disponibillização da Contracepção de Emergência. São Paulo: USP. Disponível em: http://redece.org/o-que-e-sexualidade/ Acesso em: $18 / 03 / 2015$.

RENNER, E. Menstruação. Saiba tudo sobre menstruação. [s.l; s.n.] In https://www.youtube.com/watch?v=TfM5QHEcL1Y Acesso em: 15 de março de 2013.

ZAMPIERI, M.T.C. O sexo na universidade: um estudo sobre a sexualidade e o comportamento sexual do adolescente universitário. Arte \& Ciência, São Paulo, 2004. 